\title{
Do maternal and intrauterine factors influence blood pressure in childhood?
}

\author{
P H Whincup, D G Cook, O Papacosta
}

\begin{abstract}
It has been proposed that maternal health and nutrition may be important in the development of adult cardiovascular risk, and that blood pressure may be an important intermediate step in this process. To examine the relevance of this hypothesis in contemporary British children, the relationships of several maternal factors to blood pressure were studied in 3360 children of European origin aged 5-7 years. Maternal age, height, and body mass index were all positively related to blood pressure in childhood but these relationships were abolished once the child's body build was taken into account. Maternal social class, educational attainment, and history of smoking in pregnancy showed no relationship with blood pressure in childhood. Parity showed an inverse association with blood pressure, but this appeared to be due to an association between total sibship size and blood pressure, suggesting a postnatal rather than a prenatal origin. Blood pressure was higher in children whose mothers had a history of high blood pressure but this association was no stronger than that for paternal history. Both birth weight and gestational age were inversely related to blood pressure at 5-7 years. The association between birth weight and blood pressure was attenuated by standardisation for gestational age, and the relationships between birth weight and blood pressure were similar in preterm and full term infants.

No specific associations between blood pressure and the maternal factors studied have been observed in this population. Hypotheses relating maternal factors to cardiovascular risk need to specify the timing and nature of their effects more precisely. Although the relationship between birth weight and blood pressure is not fully understood, it appears to reflect size at birth rather than fetal growth rate.
\end{abstract}

(Arch Dis Child 1992;67:1423-9)

Barker has argued that factors acting in early life may be important in the development of hypertension and cardiovascular disease in adult life. ${ }^{1}$ The environment in fetal and infant life, which is strongly influenced by maternal health and especially by maternal nutrition, may be particularly important. ${ }^{12}$ While the links between fetal and infant experience and adult cardiovascular risk are incompletely understood, it has been suggested that failure of fetal growth may play an important part. ${ }^{1}$ The demonstration of an inverse association between birth weight and blood pressure both in childhood ${ }^{3-7}$ and in adults $^{6} 89$ has suggested that blood pressure is likely to be an important link between early influences and later cardiovascular risk. It has been postulated that this hypothesis may account for both the secular trends in cardiovascular disease observed in Great Britain over the past 50 years $^{10}$ and for the current patterns of geographical variation in cardiovascular mortality. ${ }^{11-12}$ As the public health implications of the hypothesis principally concern the health and nutrition of mothers and their infants, it is important to understand the extent to which these early influences are relevant in the present generation of children.

In this report, two aspects of the hypothesis are examined in a contemporary group of children. The first is the relationship between indicators of maternal health (particularly those related to maternal nutrition) and blood pressure in childhood. The indicators of maternal health considered include age, height and body mass index, social factors (including social class, age of completion of full time education), smoking in pregnancy, parity, and a history of high blood pressure. Among these, maternal height is likely to reflect childhood influences, ${ }^{13}$ including nutrition, ${ }^{14}$ while maternal social factors are strongly related to dietary intake of both macronutrients and micronutrients during pregnancy. ${ }^{15}$ The second aspect of the hypothesis examined is the relation between birth weight and blood pressure and, in particular, the suggestion ${ }^{6}{ }^{8}$ that fetal growth rate may play a central part in this relationship.

\section{Subjects and methods}

SAMPLING PROCEDURES

The study was carried out in 10 towns in England and Wales, five with exceptionally high adult cardiovascular mortality rates (Wigan, Burnley, Rochdale, Port Talbot, and Rhondda) and five with exceptionally low cardiovascular mortality rates (Esher, Leatherhead, Chelmsford, Bath, and Tunbridge Wells). The selection of these towns has been described in detail elsewhere. ${ }^{16}$ Within each town, a sample of 10 primary schools, stratified by religious denomination and, in the case of county primary schools, by size and location, was selected. Any school unable to take part was replaced by the school matching most closely in denomination, size, and location. Within each school, two classes of children aged between $5 \cdot 0$ and 7.5 years were randomly selected to provide a sample of 50-60 children who were invited to participate. The validation of this sampling method has been described. ${ }^{\prime}$

O Papacosta 


\section{SURVEY PROCEDURES}

All measurements were made between January and July 1990 by a team of four trained nurse observers working in pairs. Standardised procedures were used throughout. Children, in groups of four, rested for a period of at least 5 minutes before the measurements described below were carried out, with subjects dressed in light clothing without shoes. Height was measured to the last complete millimetre using either a Holtain electronic stadiometer or a CMS portable stadiometer. Weight was measured to the last complete $0 \cdot 1 \mathrm{~kg}$ with a Soehnle digital electronic weighing scale. Blood pressure was measured with the child seated and the arm supported at chest level. Two blood pressure measurements were made 1 minute apart in the right arm, using the Dinamap 1846SX automated oscillometric blood pressure recorder (Critikon). ${ }^{18} 19$ All measurements were made with the child cuff size (bladder dimensions $15.5 \times 8 \mathrm{~cm}$ ), ensuring that the cuff width to arm circumference ratio of $40-50 \%$ recommended by the American Heart Association ${ }^{20}$ was met for $79 \%$ of the study population. Ethnic group was assessed on the basis of the child's appearance.

\section{QUESTIONNAIRE}

A self administered questionnaire sent to the parents of all participants on the day of examination was used to provide information on maternal and intrauterine factors. Maternal age was determined from the mother's year of birth, and refers to her age at the time of the child's birth. Maternal weight and height were recorded. Maternal social class was determined from the mother's present or most recent occupation, classified using the 1980 manual of the Office of Population Censuses and Surveys. Maternal education was assessed by asking the age at which full time education had been completed. Cigarette smoking in pregnancy, including the number of cigarettes smoked, was recorded. Mothers were asked to record the dates of birth of all older and younger siblings of the child examined; the number of older children formed the basis for assessment of parity. Inquiry was made as to whether mothers had ever had their blood pressure measured, and whether they had ever been told that their blood pressure was high. A similar question was asked of fathers. Mothers were asked to record birth weight as accurately as possible. Whether the delivery was early or late and, if so, by how many weeks, was used to determine gestational age.

\section{STATISTICAL METHODS}

Age, height, and body mass index in mothers, and gestational age and birth weight in children, have been treated as continuous variables in regression analyses, but have been grouped in fifths for presentation in figures and tables. Age, height, body mass index, and blood pressure in children have been treated as continuous variables. Maternal social class and age of completion of education have been treated as class variables; the significance of relationships with blood pressure has been based on tests for linear trend. The number of older siblings (parity) and younger siblings has also been treated as class variables; older sibling numbers of three or more and younger sibling numbers of two or more have been grouped throughout. Cigarette smoking in pregnancy and parental history of high blood pressure have been treated as $0 / 1$ variables. All results have been standardised for small differences in blood pressure measurement between observers. In this study population age, sex, height, and body mass index were all independently related to blood pressure. Standardisation for age, sex and, where appropriate, height or body mass index or both, have been carried out using standard linear regression techniques.

\section{Results}

The results are based on 3360 European children (67\% response rate) who both took part in the measurement survey and for whom parental questionnaires were returned. Analyses of maternal factors have been restricted to children living with their natural mothers $(n=3307)$; analyses of intrauterine factors are restricted to singleton births $(n=3259)$. Analyses of parental history of high blood pressure have been restricted to those subjects whose parents reported having had a blood pressure measurement made at some time (3215 mothers, 2310 fathers). Results are presented for systolic pressure throughout. Relationships for diastolic pressure are consistent with, but weaker than, those for systolic.

\section{MATERNAL FACTORS FOR BLOOD PRESSURE}

Maternal age, height, and body mass index

The relationships between maternal age, height, and body mass index and systolic blood pressure in children are presented in the figure. In a model standardised only for age and sex, all three variables show strongly positive, and statistically significant, associations with systolic blood pressure, which are largely independent of one another. However, in these children, height is correlated both with maternal age $(r=0.13)$ and with maternal height $(r=0.33)$ while body mass index is correlated with maternal body mass index $(r=0 \cdot 18)$; both of these factors are strongly associated with blood pressure in childhood. When the relationships between maternal age and blood pressure and maternal height and blood pressure are standardised for the effect of the child's height (in addition to age and sex), these associations are effectively abolished (figure). Similarly, when the relationship between maternal body mass index and blood pressure is standardised for the effect of the child's body mass index, this association is also removed (figure).

Maternal social factors, smoking in pregnancy, parity and blood pressure

The relationships between maternal social class, age at completion of full time education and smoking in pregnancy are presented in table 1. Neither maternal social class nor age at 


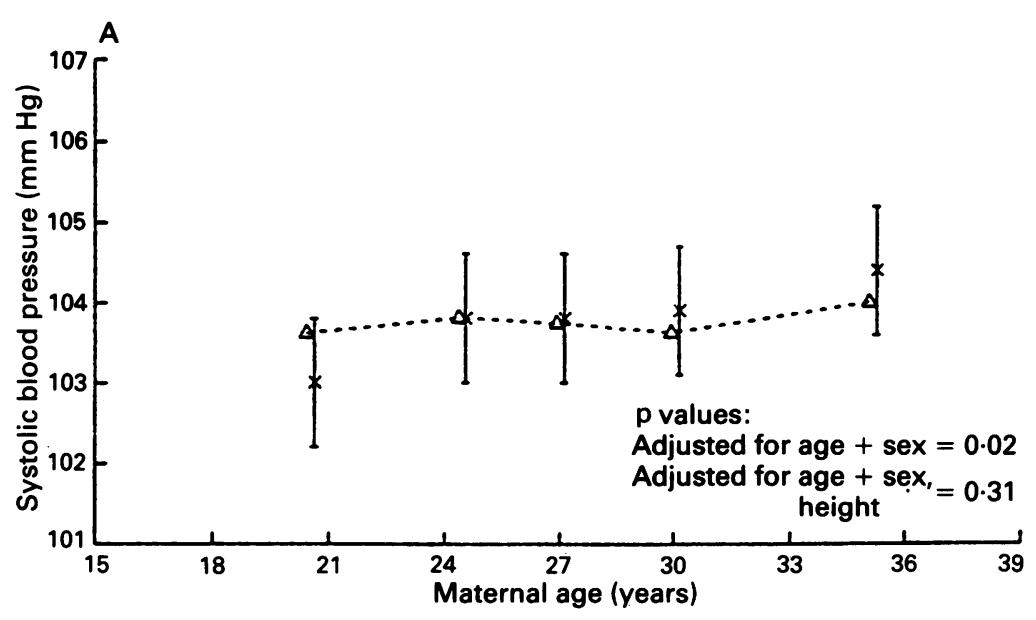

Adjustment: $x$ age sex $\Delta$ age sex height

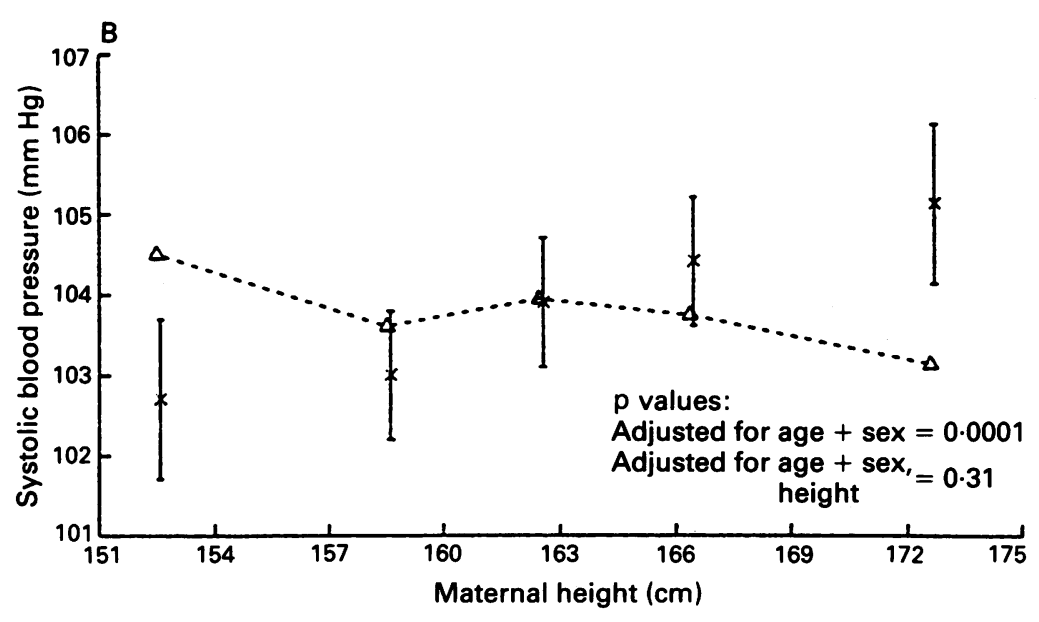

Adjustment: $x$ age sex $\Delta$ age sex height

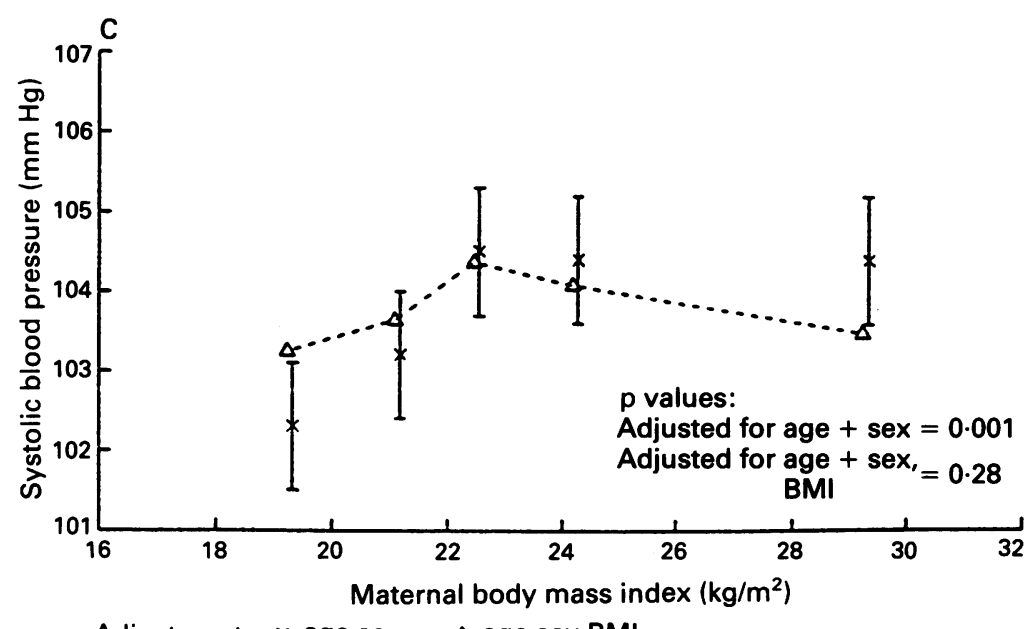

Adjustment: $x$ age sex $\triangle$ age sex BMI

(A) Maternal age, $(B)$ height, $(C)$ body mass index $(B M I)$, and systolic blood pressure in children. Results are mean and $95 \%$ confidence intervals.

completion of full time education showed a consistent relationship with blood pressure in childhood, a finding which is unchanged by using the same measures for the father or head of household (data not presented). Maternal smoking in pregnancy also shows no relationship to blood pressure in childhood. Parity, in contrast, shows an inverse, graded relationship with blood pressure, which is consistent in all groups except the small $3+$ group (table 1 ). Firstborn children have mean systolic pressures $2 \cdot 1 \mathrm{~mm}$
Table 1 Maternal factors and systolic blood pressure in children

\begin{tabular}{|c|c|c|c|}
\hline & $\begin{array}{l}\text { No of } \\
\text { children }\end{array}$ & $\begin{array}{l}\text { Systolic blood } \\
\text { pressure } \\
(\mathrm{mm} \mathrm{Hg})\end{array}$ & \\
\hline $\begin{array}{l}\text { Maternal social } \\
\text { I } \\
\text { II } \\
\text { IIINM } \\
\text { IIIM } \\
\text { IV } \\
\text { V }\end{array}$ & $\begin{array}{r}\text { class: } \\
37 \\
717 \\
1143 \\
240 \\
655 \\
150\end{array}$ & $\begin{array}{l}106 \cdot 1(1 \cdot 7) \\
103 \cdot 8(0 \cdot 4) \\
104 \cdot 3(0 \cdot 3) \\
104 \cdot 1(0 \cdot 7) \\
103 \cdot 4(0 \cdot 4) \\
104 \cdot 1(0 \cdot 9)\end{array}$ & $\begin{array}{l}\text { Test for trend } \\
p=0.30\end{array}$ \\
\hline $\begin{array}{l}\text { Maternal full ti } \\
\leqslant 16 \text { years } \\
17-20 \text { years } \\
21 \text { years }+\end{array}$ & $\begin{array}{l}\text { ime educa } \\
1863 \\
890 \\
439\end{array}$ & $\begin{array}{c}\text { ion completed: } \\
103 \cdot 7(0.3) \\
104 \cdot 4(0.4) \\
103 \cdot 6(0.5)\end{array}$ & $\begin{array}{l}\text { Test for trend } \\
p=0.62\end{array}$ \\
\hline $\begin{array}{l}\text { Maternal smoki } \\
\text { Yes } \\
\text { No }\end{array}$ & $\begin{array}{l}\text { ing in pre } \\
870 \\
2390\end{array}$ & $\begin{array}{l}\text { znancy: } \\
103 \cdot 5(0 \cdot 2) \\
104 \cdot 0(0 \cdot 4)\end{array}$ & $\begin{array}{l}\text { Test for difference } \\
\mathbf{p}=0 \cdot 29\end{array}$ \\
\hline $\begin{array}{l}\text { Parity: } \\
0 \\
1 \\
2 \\
3+\end{array}$ & $\begin{array}{r}1534 \\
1131 \\
415 \\
154\end{array}$ & $\begin{array}{l}104 \cdot 5(0.3) \\
103.4(0.3) \\
102.4(0.5) \\
103.5(0.9)\end{array}$ & $\begin{array}{l}\text { Test for trend } \\
\mathbf{p}=\mathbf{0 . 0 0 1}\end{array}$ \\
\hline $\begin{array}{l}\text { Maternal history } \\
\text { Yes } \\
\text { No }\end{array}$ & $\begin{array}{l}y \text { of high } \\
1167 \\
2048\end{array}$ & $\begin{array}{c}\text { blood pressure: } \\
105 \cdot 0(0 \cdot 3) \\
103 \cdot 1(0 \cdot 2)\end{array}$ & $\begin{array}{l}\text { Test for difference } \\
\mathbf{p}<0.0001\end{array}$ \\
\hline $\begin{array}{l}\text { Paternal history } \\
\text { Yes } \\
\text { No }\end{array}$ & $\begin{array}{l}\text { of high } \\
288 \\
2022\end{array}$ & $\begin{array}{l}\text { lood pressure: } \\
106 \cdot 0(0 \cdot 6) \\
103 \cdot 8(0 \cdot 2)\end{array}$ & $\begin{array}{l}\text { Test for difference } \\
p=0.001\end{array}$ \\
\hline
\end{tabular}

Figures are means (SE). All analyses are standardised for age and sex. Analyses are based on 3307 subjects with natural mothers, for whom a social class could be allocated in 2942, a level of educational attainment in 3192, a smoking status in pregnancy in 3260 , and a parity in 3234 . Analyses of parental history of high blood pressure are restricted to 3215 mothers and 2310 fathers who reported having had their blood pressure measured.

$\mathrm{Hg}$ higher than those whose mothers were parity 2 . It is important, however, to consider whether this association is really dependent on parity, or whether it reflects the number of older siblings on which the measure of parity is based. One way of approaching this question is to examine whether there is any relationship between the number of younger siblings and blood pressure. This relationship is examined for each number of older siblings in the columns of table 2. Mean blood pressure tends to fall with increasing numbers of younger siblings; the effect is most consistent in the largest cells, towards the top, left hand corner of the table.

To assess the strength of the independent relationships between younger sibling numbers, older sibling numbers and blood pressure, a multiple linear regression analysis including the two factors, together with age and sex, was carried out. The linear regression coefficients (representing the difference in systolic blood pressure for a single change in sibling numbers) are very similar both for older siblings $(-1 \cdot 11$ $\mathrm{mm} \mathrm{Hg}$; $\mathrm{SE} 0.24 \mathrm{~mm} \mathrm{Hg}$ ) and for younger siblings $(-1.29 \mathrm{~mm} \mathrm{Hg}$; SE $0.30 \mathrm{~mm} \mathrm{Hg})$. Results are also consistent for diastolic pressure. These findings suggest that the associations are dependent on the total number of siblings, rather than on parity. As numbers of both younger and older siblings are related to blood pressure levels in childhood, this association is likely to reflect a postnatal, rather than a prenatal, effect.

Maternal history of high blood pressure

Table 1 presents the relationship between a 
Table 2 Older siblings, younger siblings, and systolic blood pressure

\begin{tabular}{|c|c|c|c|c|c|}
\hline & & \multicolumn{4}{|c|}{ Older siblings } \\
\hline & & 0 & 1 & 2 & $3+$ \\
\hline Younger siblings & $\begin{array}{l}0 \\
1 \\
2+\end{array}$ & $\begin{array}{l}105 \cdot 4(0.5) \\
104 \cdot 3(0.4) \\
103 \cdot 8(0.7)\end{array}$ & $\begin{array}{l}104 \cdot 3(0.4) \\
101.4(0.6) \\
101.9(1.4)\end{array}$ & $\begin{array}{r}103 \cdot 2(0 \cdot 6) \\
99 \cdot 7(1 \cdot 2) \\
101 \cdot 5(2 \cdot 8)\end{array}$ & $\begin{array}{r}104 \cdot 7(1 \cdot 0) \\
99 \cdot 6(2 \cdot 1) \\
102 \cdot 6(4 \cdot 0)\end{array}$ \\
\hline
\end{tabular}

Figures are mean $(\mathrm{SE})$ systolic blood pressures $(\mathrm{mm} \mathrm{Hg}$ ). Analyses are standardised for age and sex and are based on 3234 subjects with complete data on older and younger siblings.

maternal history of high blood pressure and childhood blood pressure. Mean blood pressure levels are significantly higher in subjects with a maternal history of high blood pressure than in those without. Whether or not maternal high blood pressure was observed during the pregnancy of the child examined, makes little difference to the outcome (data not presented). The overall differences in systolic blood pressure, however, between mothers with and without a history of high blood pressure $(1.9 \mathrm{~mm} \mathrm{Hg}$, $95 \%$ confidence intervals 1.1 to $2.7 \mathrm{~mm} \mathrm{Hg}$ ) are very similar to those for a paternal history of high blood pressure $(2.2 \mathrm{~mm} \mathrm{Hg}, 95 \%$ confidence intervals 0.9 to $3.5 \mathrm{~mm} \mathrm{Hg}$ ).

\section{BIRTH WEIGHT, GESTATIONAL AGE, AND} BLOOD PRESSURE

To examine the relationships between birth weight, gestational age, and blood pressure in childhood, it is necessary to standardise results, not only for age and sex, but also for current body build. ${ }^{7}$ In this study population, height is

Table 3 Birth weight, gestational age, and systolic blood pressure

\begin{tabular}{lcl}
\hline & $\begin{array}{l}\text { No of } \\
\text { children }\end{array}$ & $\begin{array}{l}\text { Systolic blood } \\
\text { pressure }(\mathrm{mm} \mathrm{Hg} \text { ) }\end{array}$ \\
\hline $\begin{array}{l}\text { Birth weight (g): } \\
\text { 765-2950 }\end{array}$ & 659 & $104 \cdot 7(0 \cdot 4)$ \\
$2951-3230$ & 633 & $104 \cdot 7(0 \cdot 4)$ \\
$3231-3460$ & 608 & $104 \cdot 3(0 \cdot 4)$ \\
$3461-3740$ & 683 & $103 \cdot 5(0 \cdot 4)$ \\
3741-4880 & 603 & $102 \cdot 0(0 \cdot 4)$ \\
p value (linear regression) & & $<0 \cdot 0001$ \\
Gestational age (weeks): & & \\
28-30 & 13 & $107 \cdot 8(2 \cdot 7)$ \\
$31-33$ & 23 & $105 \cdot 5(2 \cdot 0)$ \\
$34-36$ & 114 & $104 \cdot 0(0 \cdot 9)$ \\
$37-39$ & 757 & $104 \cdot 6(0 \cdot 4)$ \\
$40-42$ & 2105 & $103 \cdot 4(0 \cdot 2)$ \\
$43-44$ & 47 & $104 \cdot 5(1 \cdot 4)$ \\
p value (linear regression) & & $<0 \cdot 0001$ \\
\hline
\end{tabular}

Figures are mean (SE). Analyses are standardised for age, sex, height, and body mass index and are based on 3259 singleton births, of whom birth weights are available for $\mathbf{3 1 8 6}$ subjects and gestational age for 3061 subjects.

Table 4 Birth weight, gestational age, and systolic blood pressure

\begin{tabular}{|c|c|c|c|c|}
\hline & \multicolumn{4}{|c|}{ Systolic blood pressure (mm $\mathrm{Hg})$} \\
\hline & $r$ & $S E$ & $t$ & $p$ \\
\hline $\begin{array}{l}\text { Separate analyses: } \\
\text { Birth weight } \\
\text { Gestational age }\end{array}$ & $\begin{array}{l}-2 \cdot 05 \\
-0 \cdot 35\end{array}$ & $\begin{array}{l}0.33 \\
0.09\end{array}$ & $\begin{array}{l}-6 \cdot 16 \\
-3.95\end{array}$ & $\begin{array}{l}<0.0001 \\
<0.0001\end{array}$ \\
\hline $\begin{array}{l}\text { Multiple regression } \\
\text { Birth weight } \\
\text { Gestational age }\end{array}$ & $\begin{array}{l}-1 \cdot 90 \\
-0.06\end{array}$ & $\begin{array}{l}0.42 \\
0.11\end{array}$ & $\begin{array}{l}-4.54 \\
-0.57\end{array}$ & $\begin{array}{c}<0.0001 \\
0.57\end{array}$ \\
\hline
\end{tabular}

Units of regression coefficients are $\mathrm{mm} \mathrm{Hg} / \mathrm{kg}$ or $\mathrm{mm} \mathrm{Hg} /$ week throughout. All analyses are standardised for age, sex, height, and body mass index and are based on 3061 subjects with complete data on birth weight and gestational age. correlated both with birth weight $(r=0 \cdot 18)$ and to a lesser extent gestational age $(r=0.05)$; similar associations are also observed for body mass index $(r=0.21$ and $r=0.05$ respectively). Table 3 presents the relationships between birth weight, gestational age and blood pressure, standardised for height and body mass index. Both of these factors show highly significant inverse relationships with systolic blood pressure. There is a mean difference in systolic blood pressure of $2.7 \mathrm{~mm} \mathrm{Hg}$ between the highest and lowest birthweight groups and a mean difference of $4.3 \mathrm{~mm} \mathrm{Hg}$ between children born at 28-30 weeks and those born at $40-42$ weeks. These relationships are not affected by adjustment for parity or number of siblings, or by adjustment for parental history of high blood pressure.

Other investigators examining the association between birth weight and blood pressure have suggested that fetal growth rate may play an important part. ${ }^{89}$ To examine the extent to which fetal growth rate is responsible for the relationship between birth weight and blood pressure, the relationship has been examined separately in preterm births (36 weeks or earlier) and term births ( 37 weeks or later). The rationale for such an analysis is that whereas variation in birth weight in preterm infants is strongly related to variation in gestational age $\left(r^{2}=0 \cdot 49\right)$, variation in birth weight at term, although still related to gestational age, is much less strongly so $\left(r^{2}=0 \cdot 10\right)$. Variation in fetal growth rate therefore plays a more important part in variation in birth weight at term than in preterm infants. If the association between birth weight and blood pressure is explained by fetal growth rate, it would be expected that the relation between birth weight and blood pressure would be stronger in term births than preterm births. However, the coefficients for the regression of systolic blood pressure on birth weight are very similar in preterm infants $(-1.84 \mathrm{~mm}$ $\mathrm{Hg} / \mathrm{kg}, 95 \%$ confidence interval -0.38 to -3.30 $\mathrm{mm} \mathrm{Hg})$ and in term infants $(-2.06 \mathrm{~mm} \mathrm{Hg} / \mathrm{kg}$, $95 \%$ confidence interval -1.22 to $-2.90 \mathrm{~mm}$ $\mathrm{Hg}$ ). These results provide no strong evidence of a difference in regression slopes between preterm and term infants for systolic pressure $(p=0.80)$; a similar pattern is seen for diastolic pressure $(p=0.57)$.

A more precise method of examining the importance of fetal growth rate is to examine whether standardisation of the relation between birth weight and blood pressure, for the effect of gestational age, increases the strength of the relationship (table 4). Standardisation for gestational age weakens, not strengthens, the association between birth weight and systolic blood pressure, while the association between gestational age and blood pressure disappears. These results suggest that birth weight, rather than a measure of fetal growth rate, is the factor most importantly related to blood pressure in this context.

\section{Discussion}

This study has examined the relationship between a group of maternal and intrauterine 
factors and blood pressure in a population of children from 10 towns in England and Wales with widely differing adult cardiovascular mortality rates. Although maternal age, height, and body mass index were related to blood pressure, none of these remained so after standardisation for current body build of the child. Neither maternal social class, educational attainment, nor smoking in pregnancy showed any relationship with blood pressure in childhood. Parity (based on the number of older siblings) was inversely related to blood pressure. The number of younger siblings showed an inverse association of similar strength, suggesting that number of siblings, rather than parity, was the important factor in this context. While a maternal history of high blood pressure was associated with a higher blood pressure level in childhood, the strength of this association was no greater than that for a paternal history of high blood pressure. Both birth weight and gestational age were inversely related to blood pressure once the effect of current body build was taken into account. The association between birth weight and blood pressure was similar for preterm and term infants. Moreover, standardisation for gestational age did not appear to increase the strength of the association between birth weight and blood pressure.

\section{MATERNAL FACTORS AND CHILDHOOD BLOOD PRESSURE}

Relationships between maternal factors and childhood blood pressure have been examined in several previous studies. Weak associations between maternal age and blood pressure have been described in an earlier study of 5-7 year olds $^{7}$ and in a study of 0-20 year olds. ${ }^{21}$ No important association between maternal height and blood pressure in 10 year olds was observed in the 1970 British Births Survey. ${ }^{6}$ In the present study, the effects of maternal age and height were abolished by adjustment for childhood height, while the effect of maternal body mass index was abolished by adjustment for childhood body mass index. The precise reason for these observations in uncertain. One possibility is that the associations between these maternal factors and blood pressure are confounded by childhood body size, and that they are of no importance. A second possibility is that childhood body build represents an intermediate step on a causal pathway relating maternal factors and childhood blood pressure. The results of our study do not allow us to distinguish between these possibilities. However, we have also examined the associations between paternal age, height, and body mass index and childhood blood pressure, which are very similar to those for maternal factors (data not presented). Thus, even if these maternal factors are related to childhood blood pressure, the results do not provide strong evidence for a specific maternal effect rather than a general parental effect.

No consistent relationship was observed between maternal social factors and blood pressure at 5-7 years. While several studies have provided evidence of a relationship between social class and blood pressure in British adults, with lower mean blood pressures in non-manual occupational groups, ${ }^{22}{ }^{23}$ few studies have reported a relationship between social class and blood pressure in British children. Beresford and Holland observed a $4 \mathrm{~mm} \mathrm{Hg}$ gradient in systolic pressure across paternal social class groups in 472 children aged 5-8 years, ${ }^{24}$ and Law et al recently reported that blood pressures were lower in social classes I and II in $\mathbf{4 0 5}$ children aged 4 years. ${ }^{25}$ Both our present study and an earlier study in 5-7 year olds failed to demonstrate an association between maternal social factors and blood pressure. ${ }^{7}$ The absence of associations in these studies is not simply due to the use of specifically maternal measures of social class (rather than one based on paternal social class), or to the use of a specifically occupational measure of social class (rather than one based on housing tenure or car ownership). These findings are consistent with those of MacIntyre and West, who observed that the absence of an association between social class and blood pressure in adolescents was not simply an artefact resulting from the use of an occupational social class measure. ${ }^{26}$

The inverse relationships between numbers of older siblings, numbers of young siblings and blood pressure are broadly consistent with the findings of our earlier study. ${ }^{7}$ Other investigators, however, have not confirmed this observation, ${ }^{21} 25$ although an association between the absence of siblings and high blood pressure has recently been reported in adults. ${ }^{27}$ The association between older sibling numbers and childhood blood pressure could, in theory, be explained by a prenatal, maternal effect related to parity. However, the findings of the present study (suggesting that associations both older and younger sibling numbers are equally strongly related to childhood blood pressure) strongly imply that the association is likely to be postnatal and that a specific maternal effect is unlikely.

The assessment of parental blood pressure status is based on an extremely crude measures. The association between a maternal history of high blood pressure and blood pressure in childhood is consistent with earlier reports based on direct measurement of maternal blood pressure. ${ }^{24} 25$ In this study, the association between a maternal history of high blood pressure and childhood blood pressure was of a similar strength to that of paternal history. As both of these parental measures are equally crude, this comparison should be valid even if weak. Moreover, the findings are consistent with the results of earlier studies, based on measurement of parental blood pressures, which observed associations with childhood blood pressure which were of similar strength for both maternal and paternal influences. ${ }^{24} 28$ Although one recent study has suggested that maternal blood pressure may be more important than paternal blood pressure, ${ }^{25}$ the differences between maternal and paternal relationships in that study did not approach statistical significance. Strong support for a specific association between the blood pressures of mothers and their offspring, independent of that observed for fathers, appears to be lacking at present. 
BIRTH WEIGHT, GESTATIONAL AGE, AND BLOOD PRESSURE

Several studies have observed inverse associations between birth weight and blood pressure, both in childhood ${ }^{3-7}$ and in adulthood, 689 although this has not been a universal finding. ${ }^{29}$ The magnitude of the association observed in this study is similar to that of our earlier study ${ }^{7}$ and that of Law et al in 4 year olds ${ }^{25}$ but stronger than that reported in 10 year olds from the 1970 British Births Survey. ${ }^{6}$ This discrepancy may be explained by the large number of observers and the rounding of blood pressure values in the latter study. In the British Births Survey, no association between gestational age and blood pressure was observed. However, the effect of standardisation for current body build, as used in the current study, was not described, however.

\section{IMPLICATIONS FOR HYPOTHESES EMPHASISING THE IMPORTANCE OF EARLY LIFE INFLUENCES IN THE DEVELOPMENT OF ADULT CARDIOVASCULAR DISEASE \\ Maternal factors}

No evidence has been observed in this study population to suggest the presence of specific relationships between maternal factors and blood pressure in childhood. These findings do not invalidate the general hypothesis that early influences, particulary maternal influences, may affect the risk of cardiovascular disease. The maternal measures reported here are possibly too crude, although the range of maternal heights and social circumstances is wide, despite the absence of children from inner cities in the sample. Blood pressure is possibly not the important mechanism relating maternal influences to adult cardiovascular risk; other pathways, including impaired glucose tolerance, have recently been suggested. ${ }^{2}{ }^{30} \mathrm{It}$ is also conceivable that early influences act by long term programming ${ }^{2}$ and therefore, no appreciable effects on blood pressure are to be expected in childhood. The findings emphasise that the study of early influences on cardiovascular risk in the present generation of children requires the development of more specific hypotheses for testing. In particular, the maternal factors that are important, and the nature and timing of their influence on offspring, need to be specified with greater precision. One example of this greater specificity has been the recent suggestion

Table 5 Studies relating weight and blood pressure at birth

\begin{tabular}{|c|c|c|c|}
\hline Author & Reference & No of subjects & Association \\
\hline $\begin{array}{l}\text { Term infants: } \\
\text { Moss et al } \\
\text { Kitterman et al } \\
\text { Lee et al } \\
\text { Schachter et al } \\
\text { de Swiet et al }\end{array}$ & $\begin{array}{l}31 \\
32 \\
33 \\
34 \\
35\end{array}$ & $\begin{array}{r}74 \\
45 \\
257 \\
392 \\
1740\end{array}$ & $\begin{array}{l}\text { Positive } \\
\text { Positive } \\
\text { Positive } \\
\text { None } \\
\text { Positive }\end{array}$ \\
\hline $\begin{array}{l}\text { Preterm infants: } \\
\text { Holland and Young } \\
\text { Goodman et al } \\
\text { Moss et al } \\
\text { Levison et al }\end{array}$ & $\begin{array}{l}36 \\
37 \\
31 \\
38\end{array}$ & $\begin{array}{l}15 \\
28 \\
26 \\
21\end{array}$ & $\begin{array}{l}\text { Positive } \\
\text { Positive } \\
\text { Positive } \\
\text { Positive }\end{array}$ \\
\hline $\begin{array}{l}\text { Low birthweight infants: } \\
\text { Versmold et al }\end{array}$ & 39 & 16 & Positive \\
\hline
\end{tabular}

Studies included in this list include those in which blood pressures were measured within seven days of hirth. that maternal anaemia may be related to blood pressure in offspring. ${ }^{25}$ Although preliminary results are encouraging, ${ }^{25}$ however, the hypothesis requires further exploration and substantiation.

\section{Birth weight and blood pressure}

In the earlier descriptions of the inverse relationship between birth weight and subsequent blood pressure, two general explanations for the associations have been put forward. Some authors have suggested that the relationship reflects a direct effect of intrauterine factors on the developing fetal cardiovascular system ${ }^{89}$ whereas others have suggested that the relationship is essentially due to the postnatal sequelae of low birth weight, particularly rapid postnatal growth (catch-up growth). ${ }^{5}$ Explanations in the first group include the suggestion of Gennser $e t$ al that the placental changes in intrauterine growth retardation lead to resetting of blood pressure regulation ${ }^{8}$ and Barker et al's suggestion that the processes responsible for fetal growth retardation may result in long term changes in arterial structure and compliance. ${ }^{9}$ The first of these explanations implies that blood pressure in low birth weight infants is likely to be higher by the time of birth. Those studies, however, that have measured blood pressure at, or shortly after, birth have generally observed a positive, not an inverse, relation between weight and blood pressure at that time (table 5), which argues strongly against the suggestion of Gennser et al. A common feature of both the intrauterine explanations is the importance accorded to retardation of intrauterine growth. The analyses described in this report have examined the possibility that fetal growth rate, rather than birth weight, is related to blood pressure. First, the relationship between birth weight and blood pressure has been examined in preterm and term infants, in which the contribution of fetal growth rate to differences in birth weight differs. Second, the effect of standardisation for gestational age on the relationship between birth weight and blood pressure has been examined. The results of both analyses suggest that birth weight, rather than birth weight for gestational age (a measure of fetal growth rate) is important. Interpretation of these findings must be cautious, first because birth weight and gestational age are strongly correlated $(r=0.58)$ and also because measurement of gestational age is liable to error, more so when based on recall after several years. A comparison of gestational age data collected by maternal recall at 9-11 years in 851 subjects shows a high level of agreement with data from birth records (mean difference 0.20 weeks, SD 1.3 weeks) (PH Whincup, unpublished data). Moreover, the demonstration of a relationship between birth weight and recalled gestational age again suggests that the gestational age data are at least partially valid. The results, therefore, provide no support for the earlier contention that fetal growth rate is important in explaining the association between birth weight and blood pressure. ${ }^{89}$ The biological significance of the observations remains uncertain, however. The 
findings do not resolve the question of whether the explanation for the association is prenatal or postnatal. They suggest that, if prenatal, the explanation must account for a relationship that is similar both in prematurity and growth retardation, conditions that are distinct in many aspects of their aetiology ${ }^{40}$ and clinical features. ${ }^{41}$ If the explanation is a postnatal one, the observations also cast uncertainty on the importance of early catch-up growth, ${ }^{5}$ which is more marked in preterm infants than in those with intrauterine growth retardation. ${ }^{42}$

This study was supported by a project grant from the Coronary Artery Disease Research Association (CORDA). PHW was supported by the Wellcome Trust and the British Heart Foundation and OP by the Chest, Heart and Stroke Association. We thank the members of the research team (Jenny Ashdown RGN, Wendy Cumper RGN, Sally Hirons RGN, Sharon Keegan RGN, Vivienne Howse) and the schools, parents, and children involved in the study for their cooperation.

1 Barker DJP. The fetal and infant origins of adult disease (editorial). BMJ 1990;301:1111.

2 Barker DJP. The foetal and infant origins of inequalities in health in Britain. F Public Health Med 1991;13:64-8.

3 Simpson A, Mortimer JG, Silva PA, Spears G, Williams S Correlates of blood pressure in a cohort of Dunedin seven year old children. In: Onesti G, Kim KE, eds. Hypertension in the young and old. New York: Grune and Stratton, 1981: 153-63.

4 Cater J, Gill M. The follow-up study: medical aspects. In: Illsey R, Mitchell RG, eds. Low birth weight, a medical psychologial and social study. Chichester: John Wiley, 1984: 191-205.

5 Ounsted MK, Cockburn JM, Moar VA, Redman CWG. Factors associated with the blood pressures of children born to women who were hypertensive during pregnancy. Arch Dis Child 1985;60:631-35.

6 Barker DJP, Osmond C, Golding J, Kuh D, Wadsworth $M E J$. Growth in utero, blood pressure in childhood and adult life, and mortality from cardiovascular disease. $B M \mathcal{J}$

7 Whincup PH, Cook DG, Shaper AG. Early influences on blood pressure: a study of children aged 5-7 years. BMF 1989;299:587-91.

8 Gennser G, Rymark P, Isberg PE. Low birth weight and risk of high blood pressure in adulthood. $B M \mathcal{F} 1988 ; 296$ : 1498-500.

9 Barker DJP, Bull AR, Osmond C, Simmonds SJ. Fetal and placental size and risk of hypertension in adult life. $B M \mathcal{J}$ 1990;301:259-62.

10 Osmond C, Barker DJP. Ischaemic heart disease in England and Wales around the year 2000. F Epidemiol Community Health 1991;45:71-2

11 Barker DJP, Osmond C. Infant mortality, childhood nutrition and ischaemic heart disease in England and Wales. Lancet 1986;i:1077-81.

12 Barker DJP, Osmond C. Death rates from stroke in England and Wales predicted from past maternal mortality. $B M \mathcal{Y}$

13 Tanner J, Healy M, Lockhart R, MacKenzie J, Whitehouse $R$. Aberdeen growth study. I. The prediction of adult body measurements from measurements taken each year for birth to 5 years. Arch Dis Child 1956;31:372-81.

14 Rona RJ. Genetic and environmental factors in the control of growth in childhood. Br Med Bull 1981;37:265-72.

15 Haste FM, Brooke OG, Anderson HR, Bland JM, Peacock JL. Social determinants of nutrient intake in smokers and non-smokers during pregnancy. I Epidemiol Community Health 1990;44:205-9.

16 Whincup PH, Cook DG, Papacosta O, Walker M. Blood pressure, body build and birthweight in childhood and adult cardiovascular mortality. 7 Epidemiol Community Health 1992;46:396-402
17 Whincup PH, Cook DG, Shaper AG, Macfarlane D, Walker $M$. Blood pressure in British children: associations with adult blood pressure and cardiovascular mortality. Lancet 1988;ii:890-3.

18 Ramsey M. Non-invasive automatic determination of mean arterial pressure. Med Biol Eng Comput 1979;17:11-18.

19 Whincup PH, Bruce NG, Cook DG, Shaper AG. The Dinamap 1846SX oscillometric blood pressure recorder: comparison with the Hawksley random-zero sphygmomanometer under field study conditions. 7 Epidemiol Community Health 1992;46:164-9.

20 Frohlich ED, Grim C, Labarthe DR, et al. Recommendations for human blood pressure determinations by sphygomomanometers. Report of a special task force appointed by manometers. Report of a special task force appointed by Circulation 1988;77:502A-14.

21 Higgins MW, Keller J, Moore F, et al. Studies of blood pressure in Tecumseh, Michigan. I. Blood pressure in young people and its relationship to personal and familial characteristics and complications of pregnancy in mothers. $A m \mathcal{F}$ Epidemiol 1980;111:142-55.

22 Pocock SJ, Shaper AG, Cook DG, et al. Social class differences in ischaemic heart disease in British men. Lancet 1986;ii: 197-201

23 Marmot MG, Rose G, Shipley M, Hamilton PJS. Employment grade and coronary heart disease in British civil servants. F Epidemiol Community Health 1978;32:244-9.

24 Beresford SAA, Holland WW. Levels of blood pressure in children: a family study. Proceedings of the Royal Society of

25 Law CM, Barker DJP, Bull AR, Osmond C. Maternal and fetal influences on blood pressure. Arch Dis Child 1991;66: $1291-5$

26 MacIntyre S, West P. Lack of class variation in health in adolescence: an artefact of an occupational measure of social class? Soc Sci Med 1991;32:395-402.

27 Trevisan M, Krogh V, Klimowski L, et al. Absence of siblings-a risk factor for hypertension? N Engl f Med 1991; 324:1285

28 Zinner SH, Rosner B, Oh W, Kass EH. Significance of blood pressure in infancy. Familial aggregation and predictive effect on later blood pressure. Hypertension 1985;7:411-6.

29 Seidman DS, Laor A, Gale R, et al. Birth weight, current body weight, and blood pressure in late adolescence. $B M \mathcal{F}$ 1991;302:1235-6.

30 Hales CN, Barker DJP, Clark PMS, et al. Fetal and infant growth and impaired glucose tolerance at age 64. BMF

31 Moss AJ, Duffie ER, Emmanouolides G. Blood pressure and vasomotor reflexes in the newborn infant. Pediatrics 1963; 32:175-9.

32 Kitterman JA, Phibbs RH, Tooley WH. Aortic blood pressure in normal newborn infants during the first 12 hours of life. Pediatrics 1969;44:959-68

33 Lee Y-H, Rosner B, Gould JB, Lowe EW, Kass EH. Familial aggregation of blood pressures of newborn infants and their mothers. Pediatrics 1976;58:722-9.

34 Schachter J, Kuller LH, Perkins JM, Radin ME. Infant blood pressure and heart rate: relation to ethnic group (black or white), nutrition and electrolyte intake. Am $\mathcal{f}$ Epidemiol 1979;110:205-18

35 de Swiet M, Fayers P, Shinebourne EA. Systolic blood pressure in a population of infants in the first year of life: the Brompton study. Pediatrics 1980;65:1028-35.

36 Holland WW, Young IM Neonatal blood pressure in relation to maturity, mode of delivery and condition at birth. $B M \mathcal{F}$ to maturity, mo

37 Goodman HG, Cumming ER, Raber MB. Photocell oscillometer for measuring systolic blood pressure in the newborn. Am $\mathcal{F}$ Dis Child 1962;103:152-9.

38 Levison H, Kidd BSL, Gemmell P, et al. Blood pressure in normal full-term and premature infants. Am $\mathcal{F}$ Dis Child 1966;111:374-9.

39 Versmold HT, Kitterman JA, Phibbs RH, Gregory GA, Tooley WH. Aortic blood pressures during the first 12 hours of life in infants with birthweight 610 to 4220 grams. Pediatrics 1981;67:607-13.

40 Lumley J. Epidemiology of prematurity. In: Yu WYH, Wood EC, eds. Prematurity. London: Churchill Livingstone, 1987:1-24.

41 Usher R, McLean F, Scott KE. Clinical significance of gestational age and an objective method for its assessment. Pediat Clin North Am 1966;13:835-48.

42 Cruise MO. A longitudinal study of the growth of low birthweight infants. Pediatrics 1973;51:620-8. 